\title{
THE DETECTION AND ESTIMATION OF SMALL QUANTITIES OF MALTOSE IN THE PRESENCE OF DEXTROSE.
}

\author{
By JULIAN L. BAKER, F.I.C., AND W. D. DICK, H.I C. \\ (Read at the Meeting, November 2, 1904.)
}

LAST year the Council of this Society honoured us by suggesting that we should submit L. Grimbert's method for detecting small quantities of maltose in presence of dextrose (Journ. Pharm. Chim., 1903, xvii,, 225, and this Journal, 1903, 151) to a critical examination.

Lepine and Boulud (Comptes Rend. Soc. Biol., December, 1901) devised a method for detecting dextrose in presence of maltose which consisted in treating the phenyl osazones of these sugars with ether. It was claimed that maltosazone was dissolved and could be recognised by its crystalline form. Grimbert (loc. cit.), however, stated that maltosazone is as insoluble in ether as dextrosazone. He recommended the following method as capable of detecting maltose in a 0.1 per cent. solution containing $0 \cdot 1$ to 1 per cent. of dextrose : 20 c.c. of the solution containing the two sugars are treated with 1 c.c. of phenylhydrazine and 1 c.c. of glacial acetic acid, and the whole heated on the water-bath for an hour, and then cooled. The mixed osazones are washed with cold water and dried, then washed with benzene until the washings are colourless, and dried at $100^{\circ} \mathrm{C}$. They are then triturated in a mortar with the smallest possible amount of acetone diluted with its own volume of water, and, on allowing the filtrate to stand, crystals, with the characteristic form and meltingpoint $\left(196^{\circ}\right.$ to $198^{\circ} \mathrm{C}$.), are deposited. Or, the osazones may be heated in a minute amount of water for five minutes on the water-bath, and then rapidly filtered, leaving the dextrosazone, which is much more insoluble in hot water, on the filter.

In the course of this investigation we employed freshly distilled phenylhydrazine 
and pure maltose and dextrose. To test Grimbert's method systematically, pure specimens of maltosazone (melting-point, $195^{\circ}$ to $200^{\circ} \mathrm{C}$.) and dextrosazone (meltingpoint, $200^{\circ}$ to $202^{\circ} \mathrm{C}$.) were prepared and the relative solubilities examined in different solvents.

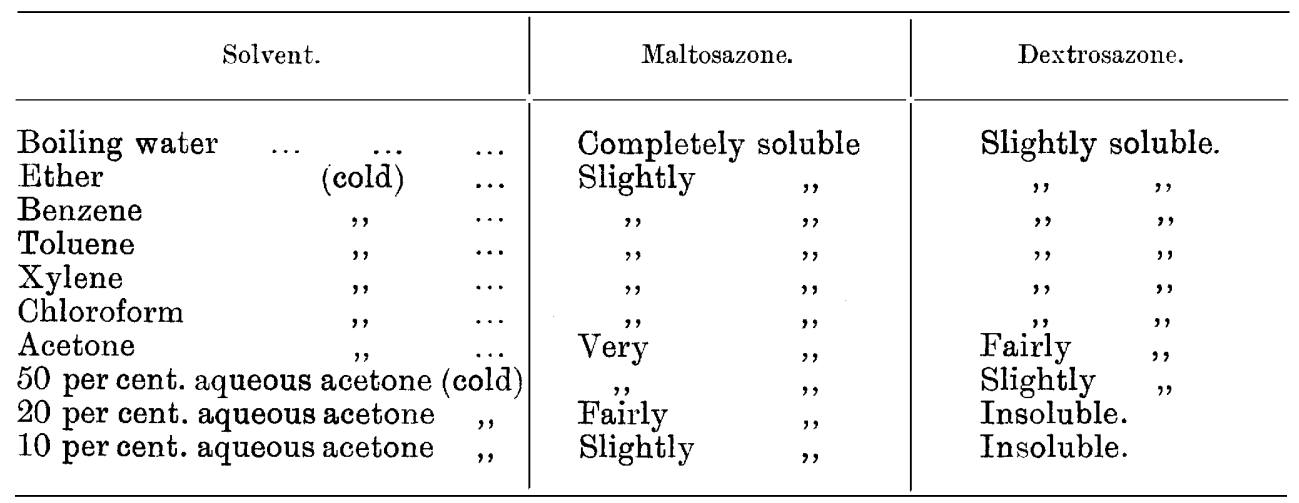

It will be noticed that 50 per cent. aqueous acetone dissolves dextrosazone to some extent, and, therefore, throughout these experiments we used 20 per cent. acetone.

The solubility of pure maltosazone in benzene, in our opinion, precludes the use of this solvent for removing the tarry matters produced during the formation of the osazones, for it was found that when a prepared mixture of the pure osazones of maltose and dextrose, in which the former was present in small quantity, was washed with cold benzene the maltosazone was for the most part dissolved. Moreover, the solubility of the impure osazones of maltose and dextrose, such as results when the mixed sugars are converted into osazones, is very marked in cold benzene. This portion of Grimbert's process had to be abandoned, and we endeavoured to prepare the osazones in such a manner that the tarry products of the reaction were reduced to a minimum. Clean osazones may be obtained by heating 20 c.c. of 5 per cent. solution of the mixed sugars contained in a round-bottomed flask fitted with a tube condenser with 1 gramme of freshly distilled phenylhydrazine and 1.5 c.c.of 50 per cent. acetic acid for three-quarters of an hour in a boiling water-bath. The osazones are then cooled and filtered through a Gooch crucible, washed with 25 c.c. of cold water, and then with 10 c.c. of cold 5 per cent. aqueous solution of acetone. When the preparation is well drained, it is mixed in the Gooch crucible with 10 to 15 c.c. of cold 20 per cent. acetone, and filtered. On standing, the filtrate deposited a mixture of maltosazone and a little dextrosazone. The former, if present in sufficient quantity, could be easily identified, when examined under the microscope with a $\frac{1}{4}$-inch or $\frac{1}{8}$-inch objective, by its characteristic ribbon-like crystals. Working under these conditions, dextrose, when mixed with 15 per cent. of maltose, gave definite indications of maltosazone, 10 per cent. of maltose was doubtful, and no satisfactory separation of maltosazone could be obtained when dextrose was mixed with $2 \frac{1}{2}$ and 5 per cent. of maltose.

When mixtures of the pure osazones of maltose and dextrose were made in varying proportions and triturated with 20 per cent. acetone, it was easy to detect 5 and 10 per cent. maltosazone in the filtrate. This illustrates the influence which 
the by-products of the osazone reaction has on the crystalline structure of maltosazone, and this would be still more marked if the sugars themselves were impure. The difficulty of preparing pure maltosazone from the products of the hydrolysis of starch is well known.

Attempts were made to estimate the amount of maltose in a mixture of this sugar and dextrose by converting into the osazones in the manner described above. After washing with the 25 c.c. of cold water the osazones were dried until constant in weight in the water-oven, and then washed with 20 c.c. of cold 20 per cent. acetone. The osazone was again dried and weighed, and it was hoped that when working under these standard conditions the difference in weight due to the loss of maltosazone might be a measure of the maltose present. The results were very variable, and, after many trials, we were forced to the conclusion that no process of estimation could be based on the difference in solubility in 20 per cent. acetone of maltosazone and dextrosazone.

We next tried to see if it was possible to estimate small quantities of maltose by acid hydrolysis. Numerous experiments were carried out to determine the proper conditions for the inversion of maltose. When 10 c.c. of a 2 per cent. solution of maltose are heated in a flask fitted with a tube condenser with 1 c.c. of strong hydrochloric acid (specific gravity 1.16) and 10 c.c. of water for ninety minutes in a boiling water-bath, the contents of the flask being then cooled and neutralized, the inversion was completed to the extent of 96.5 per cent. As the object of the investigation was to estimate small quantities (from $2 \frac{1}{2}$ to 15 per cent.) of maltose in presence of dextrose, this amount of uninverted maltose would be without any marked influence on the results. Moreover, under these conditions there were practically no reversion products formed. Having obtained the inversion constant for maltose, mixtures containing known amounts of maltose and dextrose were made, the gravity of the solution of the mixed sugars was taken, and the grammes per 100 c.c. calculated by the 3.86 divisor. Ten c.c., or other appropriate volume, of the sugar solution was then weighed and the solid matter present calculated. The reducing power in terms of dextrose was determined before and after inversion. The percentage of maltose found was calculated from the formula :

$$
M=\frac{\left(R-R_{1}\right)}{100-62 \cdot 1} \times 100,
$$

in which $R$ and $R_{1}$ are the reducing powers in terms of dextrose after and before inversion respectively. The constant 62.1 is the reducing power of anhydrous maltose, dextrose being taken as 100 .

\begin{tabular}{c|c|c|c}
\hline $\begin{array}{c}\text { Approximate Per- } \\
\text { centage by Weight of } \\
\text { added Maltose to } \\
\text { Dextrose. }\end{array}$ & $\begin{array}{c}\text { Reducing Power } \\
\text { in terms of } \\
\text { Dextrose before } \\
\text { Inversion. }\end{array}$ & $\begin{array}{c}\text { Reducing Power } \\
\text { in terms of } \\
\text { Dextrose after } \\
\text { Inversion. }\end{array}$ & $\begin{array}{c}\text { Percentage of } \\
\text { Maltose found. }\end{array}$ \\
\hline $2 \cdot 5$ & $99 \cdot 6$ & $100 \cdot 1$ & $1 \cdot 3$ \\
$5 \cdot 0$ & $97 \cdot 9$ & $100 \cdot 15$ & $5 \cdot 9$ \\
$10 \cdot 0$ & $96 \cdot 5$ & $100 \cdot 2$ & $9 \cdot 9$ \\
15.0 & $94 \cdot 07$ & $100 \cdot 1$ & $15 \cdot 8$ \\
\hline
\end{tabular}


These results, which are the mean of many determinations, are fairly satisfactory, for it will be clear that a very small experimental error in the determination of the reducing powers will seriously affect the percentage of maltose.

If maltose and dextrose are the only sugars in the mixture which is being analysed, the inversion method will afford fairly accurate results; but should any other body be present, capable of forming reducing sugars on hydrolysis (dextrin, for example), the difference in the reducing powers before and after inversion would be calculated as maltose.

Since the number of reactions which can be utilized for the estimation of maltose in presence of dextrose is very limited, we decided to see if anything could be done by employing yeasts of selective fermentative functions. Hansen and other investigators have shown that certain yeasts, amongst them Saccharomyces Marxianus and Ludwigii, possess the property of fermenting dextrose and not maltose. We employed S. Marxianus. It was obviously necessary to ascertain (1) if the culture of $S$. Marxianus would have any reverting influence on dextrose, and (2) if a maltose hydrolyzing enzyme was present. Three hundred c.c. of a 1 per cent. solution of dextrose to which some yeast extract had been added were fermented for five days at $25^{\circ} \mathrm{C}$. About 60 per cent. of the dextrose was fermented. The remaining sugar had the constants $(\alpha)_{D_{3} \cdot S 6}=52 \cdot 1$ and $R_{3 \cdot s t}=97 \cdot 8$ per cent. dextrose (corrected for added yeast extract). Two hundred c.c. of a 1 per cent. solution of maltose was treated with S. Marxianus under similar conditions. At the end of five days the solution, which had undergone no change in concentration, had the constants $(a)_{D} 3 \cdot 93=134 \cdot 5$, and $R_{3 \cdot 93}=101 \cdot 2$ per cent. of maltose.

The two possibilities, therefore, have no foundation, hence it was perfectly safe to use the culture of S. Marxianus for the removal of dextrose from a mixture of that sugar and maltose.

The method of experiment was as follows: To 100 c.c. of a 2 to 5 per cent. solution of the mixed sugars 5 c.c. of sterile yeast extract (prepared by boiling washed brewery yeast with water and filtering) were added, and the solution infected with a pure culture of $S$. Marxianus and allowed to ferment for five days at $25^{\circ} \mathrm{C}$. At the end of this time the solution was treated with a little alumina cream, filtered, boiled to remove the alcohol, and its gravity, specific rotatory power, and reducing power in terms of dextrose determined.

The undermentioned results were obtained :

Before Fermentation. Constants of Mixtures of varying Proportions of Maltose and Dextrose.

\begin{tabular}{|c|c|c|c|}
\hline $\begin{array}{c}(\alpha)_{\mathrm{D}_{3 \cdot 86}} \\
56 \cdot 5 \\
59 \cdot 1\end{array}$ & $\begin{array}{c}\mathrm{R}_{3 \cdot \text { si }} \text { glucose } \\
\mathbf{9 7 \cdot 3} \\
96 \cdot 6\end{array}$ & $\begin{array}{c}(\alpha)_{\mathrm{D}_{3} \cdot 56} \\
111 \cdot 3 \\
88 \cdot 0\end{array}$ & $\begin{array}{l}\mathrm{R}_{3 \cdot 56} \text { glucose } \\
34 \cdot 7 \\
63 \cdot 1\end{array}$ \\
\hline \multicolumn{4}{|c|}{ (Fermented for sixty hours) } \\
\hline $56 \cdot 4$ & $97 \cdot 4$ & $82 \cdot 0$ & $70 \cdot 0$ \\
\hline $56 \cdot 4$ & $97 \cdot 4$ & $108 \cdot 5$ & $37 \cdot 6$ \\
\hline
\end{tabular}

The increase in the specific rotatory power and the marked drop in the reducing power after fermentation may be regarded as evidence of the presence of maltose. 
In order to confirm this deduction, the sugar remaining in solution was treated with phenylhydrazine acetate in the water-bath for three-quarters of an hour and the small amount of dextrosazone formed removed by filtration. Maltosazone separated from the filtrate in all the above experiments, and after it was recrystallized from a small quantity of boiling water it had the characteristic ribbon-like appearance of maltosazone and melted at $180^{\circ} \mathrm{C}$. The melting-point is low for maltosazone, but it is well known that a small quantity of dextrosazone considerably depresses the melting-point of the former.

The conclusions that we have arrived at in this work may be summarized as follows:

1. L. Grimbert's method (loc. cit.) for removing the subsidiary products of the osazone reaction by benzene failed to give satisfactory results in our hands owing to the solubility of the impure maltosazone in this solvent. A small quantity of cold 5 per cent. aqueous acetone removes most of the impurities, witbout to any great extent dissolving the maltosazone. By relying on the osazone reaction alone, it was only possible to detect quantities of 15 per cent. maltose in mixtures of this sugar and dextrose with any degree of certainty.

2. Unsuccessful efforts were made to estimate small quantities of maltose in presence of dextrose by converting into osazones, and dissolving the maltosazone out with 20 per cent. acetone.

3. Small quantities of maltose, in a mixture of maltose and dextrose, may be estimated with a fair degree of accuracy by determining the reducing power before and after inversion under standard conditions, which are described. The difference in reducing powers may be due to maltose, but, in order to be certain on this point, the solution of the mixed sugars is fermented with $S$. Marxianus. A rise in the specific rotatory power and fall in the reducing power is additional evidence of the presence of maltose. To place the matter beyond doubt, the solution after fermentation is converted into maltosazone, and this compound identified as such by its microscopical appearance and melting-point.

Should dextrinous bodies of high molecular weight be present in the solution to be analysed, they must be removed before the inversion and fermentation. This may be done by repeated precipitations in alcohol, or mixtures of alcohol and acetone.

The methods described above are being used by the authors in an investigation on the products of the acid hydrolysis of starch.

\section{Discussion.}

The President (Mr. Fairley) having invited discussion,

Dr. Thorne said that, when this set of carbohydrates occurred together in a mixture, even their identification, not to mention their determination, was a very difficult problem, towards the elucidation of which the author's work was certainly an important step. It seemed to him, however, that dextrin, if present, would cause a difficulty in the fermentation process, quite as great as that which, as stated in the paper, it caused in the reduction process. He must say that he had not found 
fermentation processes altogether satisfactory. In his experience, the supposition that a given yeast fermented a substance completely, or left another substance entirely unfermented, did not work out in practice to anything like the full degree.

The author's own experience in the two days' fermentation experiment showed that in that case the dextrose had not been completely fermented, and the maltose was not left absolutely intact. Although with mixtures of dextrose and maltose numbers could be obtained which were approximately correct, it seemed to him that, if dextrin were present, and especially if cane-sugar were also present, the interference of these products would make even the identification of small quantities of maltose very difficult, if not doubtful. Possibly the authors might have something to say with regard to the influence of dextrin and of cane-sugar, if present, on these fermentation results.

Mr. Chapman said that this communication was of special interest, inasmuch as it represented the first fruits of a scheme which had been adopted by the Society with the object of fostering and promoting investigation in connection with analytical chemistry, and of securing the revision of processes which on the face of them seemed likely to be useful to practising chemists, but which for one reason or another could not be justifiably accepted without some further examination. If the future communications to the Society under this scheme were as useful and as well carried out as the one to which they had just listened they would have reason to congratulate themselves on having conceived the idea of such a scheme. Mr. Baker had remarked that he and his colleague had, to use his own expression, "gone beyond their commission"; but they would be very glad if others would also "go beyond their commissions" with as good results as the present authors had. So far as this paper was concerned, he (Mr. Chapman) must confess that he would have liked to have heard a little more about the acetone method, particularly as to its ability to detect, say, a small quantity of dextrose in the presence of a comparatively large quantity of maltose. Perhaps the authors had some further results bearing on this point. He thought there could be no doubt that the adoption of these three methods and a careful consideration of the results obtained would enable the one sugar to be estimated in presence of the other with a fair degree of accuracy. With regard, however, to the fermentation process, it must be borne in mind that the employment of a pure culture of any organism was apt in unpractised hands to be followed by misleading results. It was well known how prone such cultures were to become impure, and even a slight contamination might after a little time become serious. Those who were accustomed to working with pure cultures knew how to check their purity and to ascertain whether they had become contaminated, and they knew, also, what those unaccustomed to such matters might, perhaps, not know, namely, how necessary it was that such checking should be systematic. The detection of contamination was much more difficult than in the case of a chemical reagent, and could, practically speaking, only be carried out by those who were constantly handling such pure cultures. In short, the biological method was in many cases very useful ; but it was apt to be dangerous in inexperienced hands. With regard to other points raised in the paper, he had found the reducing power of maltose in terms of dextrose to be distinctly lower than 62 , and also that the melting-point of maltosazone was lower than the authors had found. He had purified maltosazone over and over again 
from every liquid from which it would crystallize, and had never been able to get the melting-point as high as $202^{\circ}$.

Mr. BAKER, in reply, said that in the case of products consisting presumably of maltose, dextrose and dextrin, it was suggested that the dextrin should be first removed by precipitation with alcohol, or acetone, or a mixture of the two. With a mixture of maltose, dextrose, and cane-sugar, the cane-sugar should be inverted by yeast at about $55^{\circ}$ C., and then fermented by S. Marxianus. In response to Mr. Chapman's desire for further information about the treatment of the osazones with acetone, he might say that after some experiments it had been found that dextrosazone was very appreciably soluble in 50 per cent. acetone, and by a process of reduction it was found that much better results were obtained with 20 per cent. acetone, in which dextrosazone was practically insoluble. Mixtures of maltose and dextrose had been made containing $2 \frac{1}{2}, 5,10$ and 15 per cent. of maltose, and it was found that, extracting with 20 per cent. acetone, a mixture of 10 or 15 per cent. of maltose in presence of dextrose could be detected, but not $2 \frac{1}{2}$ or 5 per cent. When the osazones were first isolated and then mixed, these smaller quantities could be detected, but it was not possible when the sugars themselves were mixed, owing to the formation of subsidiary reaction products. Another point to which attention might be drawn was that in the original method of Grimbert the benzene used removed practically all the maltosazone when this substance was present in small amount. With 15 or 10 per cent. of maltose it did not matter, but with $2 \frac{1}{2}$ or 5 per cent. the method could not be used. Mr. Chapman's remarks on the use of biological reagents were perfectly just, but, as had been pointed out, practically no strong evidence of the presence of the maltose was to be obtained by inversion, and some other method was absolutely necessary. The only one applicable in the present instance, so far as he was aware, was the use of a biological reagent-namely, S. Marxianus. In sugar analysis it seemed that such unusual reagents must sometimes be resorted to, but he quite agreed that it was well to recognise their danger in unaccustomed hands. The melting-point of maltosazone depended a good deal upon how the determination was made. If the sulphuric acid was heated very slowly, the maltosazone invariably melted at about $190^{\circ} \mathrm{C}$. If it were heated quickly, according to Fischer's instructions, pure maltosazone would melt at $195^{\circ}$ to $200^{\circ} \mathrm{C}$. His own practice was to take the melting-point when the sintered mass ran together, and under those conditions he found the melting-point of pure maltosazone to be $195^{\circ}$ to $200^{\circ}$, and that of dextrosazone $202^{\circ} \mathrm{C}$.

Mr. Chapman : With dextrosazone it is much sharper than with maltosazone?

Mr. BAKER: Yes.

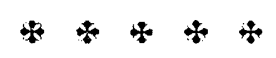

